\title{
Smart Car Parking Mobile Application based on RFID and IoT
}

https://doi.org/10.3991/ijim.v13i05.10096

\author{
Aekarat Saeliw ${ }^{(凶)}$, Watcharasuda Hualkasin, Supattra Puttinaovarat \\ Prince of Songkla University, Surat Thani, Thailand \\ aekarat.s@psu.ac.th \\ Kanit Khaimook \\ Ramkhamhaeng University, Bangkok, Thailand
}

\begin{abstract}
The common problem that is mostly found in urban areas and the organizations that provide services to large numbers of people such as government agencies, universities, department stores and hospitals, is the insufficient car parking areas. This problem is the result of the continually increasing number of vehicles. Furthermore, the car parking management is also insufficient, and the service users thus waste their time and fuel searching for an available parking space. The objective of this research was to develop a mobile application for smart car parking using Radio-Frequency Identification (RFID) and the Internet of Things (IoT), which can detect the available parking spaces, thereby saving time for people. Moreover, the parking area management is more efficient as it minimizes the limitations of the conventional system in which the users have to access a web application that is unable to automatically alert them when the status of a parking space has changed. Additionally, the data can be applied to the management and planning, such as analyzing the numbers of vehicles daily to compare with the number of parking spaces to determine whether it is sufficient or not in order to appropriately improve and provide more parking spaces.
\end{abstract}

Keywords_Smart Car Parking, Mobile Application, IoT, RFID

\section{Introduction}

Nowadays, Thailand and countries worldwide use more cars, which leads to many problems such as road accidents, [1] traffic congestion in many areas [2], and waste of fuel and energy [3]. One of the significant problems that agencies and organizations often encounter is the problem of insufficient car parking [4]. Moreover, the car parking management is inefficient as most parking lots apply a conventional management system, managed by staff or manpower. Furthermore, most places have no management system, therefore the problem still exists. The agencies and organizations that encounter this problem are department stores, government offices, and educational institutions where large numbers of vehicles access the area daily. 
People waste time looking for a place to park, which also wastes their fuel. Based on the review of previous research studies relevant to the parking lot systems or parking lot management currently used in Thailand and other countries, it was indicated that most still apply the conventional management system in which the staff record the data and handle the parking lot. The problem is that it cannot identify the number of cars accessing the area and the exact location of available parking spaces. As a result, people waste their time to find the available space. However, because of the advance of information technology and the internet, there has been the development of equipment and technologies such as sensors, RFID [5][6] devices, and microcontrollers [7]; thus, researchers now have more alternatives to apply the developed technology and 4.0 technologies to enhance the efficiency of the current infrastructure [8]. This is consistent with the policies of Thailand and other countries that promote the agencies and organizations to utilize technologies to create Smart Cities [9][10] to accelerate the efficient and quick processes and operations.

The research studies relevant to the smart car parking development revealed that electronic components and computer and network technology can be applied to develop the smart car parking in many ways. Application development is divided into three main parts: the development of the web application, the social media application, and the data transfer via SMS. The study and analysis of the developed system showed that there were many limitations. For example, the functioning of the web application is unable to display results or automatically notify users (Push Notification) if they are not using the application at that moment. The data transfer via SMS only allows the transfer of locations using the letters of the alphabet, so it is inconvenient for the users as they will not know the location of the available parking spaces.

In order to resolve these problems, the researcher proposed the design and development of a smart car parking system using RFID and IoT to facilitate the efficient car parking management. This would help the service users to check the available parking spaces via a mobile application that includes the available locations and number of available spaces, which will allow the users to make decisions and minimize the problems of parking, as well as impress the users.

\section{$2 \quad$ Literature Review}

The study of previous research relevant to the development of smart car parking showed that electronic components and computer and network technology were applied to develop the smart car parking in many ways. There was the research to apply RFID to develop the smart car parking which used Raspberry Pi, infrared sensors, and RFID. The software used was HTML5, CSS, Bootstrap, and Google App Engine. The ability of the system was to check the available parking spaces. The user could access the system via three channels: the website, mobile application, and Twitter. The study illustrated that the limitation of this research was that the results displayed on Twitter only, not on the developed website or mobile application. To check the available parking spaces the users had to wait for the text from Twitter. If 
no text was sent, the data of the available parking spaces would not be available [11]. The function of RFID was to search for the available parking space and calculate the time and expense for the users. However, this research did not display the results or present the results of the mobile application program, but only the structural architecture of the system, and thus it could not be compared to other relevant research. Besides this, it could not be analyzed if the program was applicable [12].

Moreover, RFID and IoT were combined to develop a car parking system by using sensors based on Raspberry Pi to detect the parking. For the web application, the users could reserve the parking space if it was available. Nevertheless, the limitation of the developed system was that the customary program was more suitable for personal computers than mobile devices, particularly smartphones as the various screen sizes did not support the design. Furthermore, the web application program required the users to $\log$ in to the website every time because Push Notification was unavailable if a user was not using the web application at that time [13]. In addition, the car parking program using RFID and automatic SMS would send a message to the user if the sensor detected an available parking space. However, SMS was only in the text format, without the location or photo of the parking space, so the users needed to know the location of each parking space, otherwise they were unable to park at the exact location [14][15][16]. Analysis results indicated that the advantage of this system was that it was applicable to all places, whereas the limitation was that data transfer via GSM caused the delay of sending the data.

When considering other technologies, it was found that one camera that detected many cars was used to check the parking area. However, the limitation was that the weather affected the system. Therefore, the camera should be installed at the appropriate spot. The strength of the system was that the users could see the parking via real-time video; however, the users had to recheck again if there were any parking spaces available [17]. In addition, Bluetooth technology was employed. The strength of this system was the low cost since Bluetooth Reader is inexpensive, but there was the limitation on the distance because Bluetooth has a limited range when sending data; RFID is able to send data in a wider range. As a result, a Bluetooth system was less appropriate to use [18].

From all relevant research studies, the conclusion regarding the hardware technology used in the development and application that were the development results are shown in Table 1. The analysis showed that RFID was mostly used in car parking management by developing it as web application. However, the weakness was that it could not send push notifications, which meant that the users must be logged in all of the time or frequently, which wasted their time. In addition, social media was used by sending data via social media applications such as Twitter and Line. Nevertheless, the weakness was that the users had to wait for Twitter to send the text, otherwise the users could not access the data regarding available parking spaces. Another chapter includes the conceptual framework; therefore, there was no analysis of strengths and weaknesses. 
Table 1. Literature Review Summary

\begin{tabular}{|c|c|c|c|c|c|c|c|}
\hline \multirow{2}{*}{ Reference } & \multicolumn{3}{|c|}{ Hardware Technology } & \multicolumn{4}{c|}{ Application Result } \\
\cline { 2 - 8 } & RFID & Camera & Bluetooth & $\begin{array}{c}\text { Web } \\
\text { Application }\end{array}$ & $\begin{array}{c}\text { Mobile } \\
\text { Application }\end{array}$ & $\begin{array}{c}\text { Social } \\
\text { Media }\end{array}$ & $\begin{array}{c}\text { Without } \\
\text { Application }\end{array}$ \\
\hline$[11]$ & $/$ & & & $/$ & & $/$ & \\
\hline$[12]$ & $/$ & & & & & & $/$ \\
\hline$[13]$ & $/$ & & & $/$ & & & \\
\hline$[14]$ & $/$ & & & & & & $/$ \\
\hline$[15]$ & $/$ & & & & & & $/$ \\
\hline$[16]$ & $/$ & & & & & & $/$ \\
\hline$[17]$ & & $/$ & & & & & $/$ \\
\hline$[18]$ & & & $/$ & & & & $/$ \\
\hline Our Purpose & $/$ & & & $/$ & $/$ & $/$ & \\
\hline
\end{tabular}

\section{$3 \quad$ Methodology}

This research proposes the development of a smart car parking mobile application based on RFID and IoT that uses microcontrollers, Arduino ESP8266, and Sensor Ultrasonic Module HY-SRF05 Distance to enhance the system. The sensor is able to examine the availability or non-availability of the parking spaces, which facilitates the users' search. The development framework is shown in Figure 1. The sensor detects the status of each parking space and determines if there is a car in the area or not. If there is no car and the space is available, it shows ' 0 ' (Empty). If it is unavailable or there is a car present, it shows ' 1 ' (Unavailable). Then, the system updates the status in the database. When a user accesses the car parking area, the sensor detects the car in order to transfer the data to the microcontroller (Arduino), which then transfers the data via Wi-fi to the server to record the data in the database and show the status on the mobile application and Line application. The hardware and software used in the system is shown in Table 2. It is classified into two parts: the hardware and software for the client device and the hardware and software for the server, which have different details. For the client part, it is comprised of two parts, which are the sensor to detect data and a user's smartphone, which can be Android only. For the server, it consists of the specific software such as the operating system, software program, connection to the microcontroller, web server, and database. 


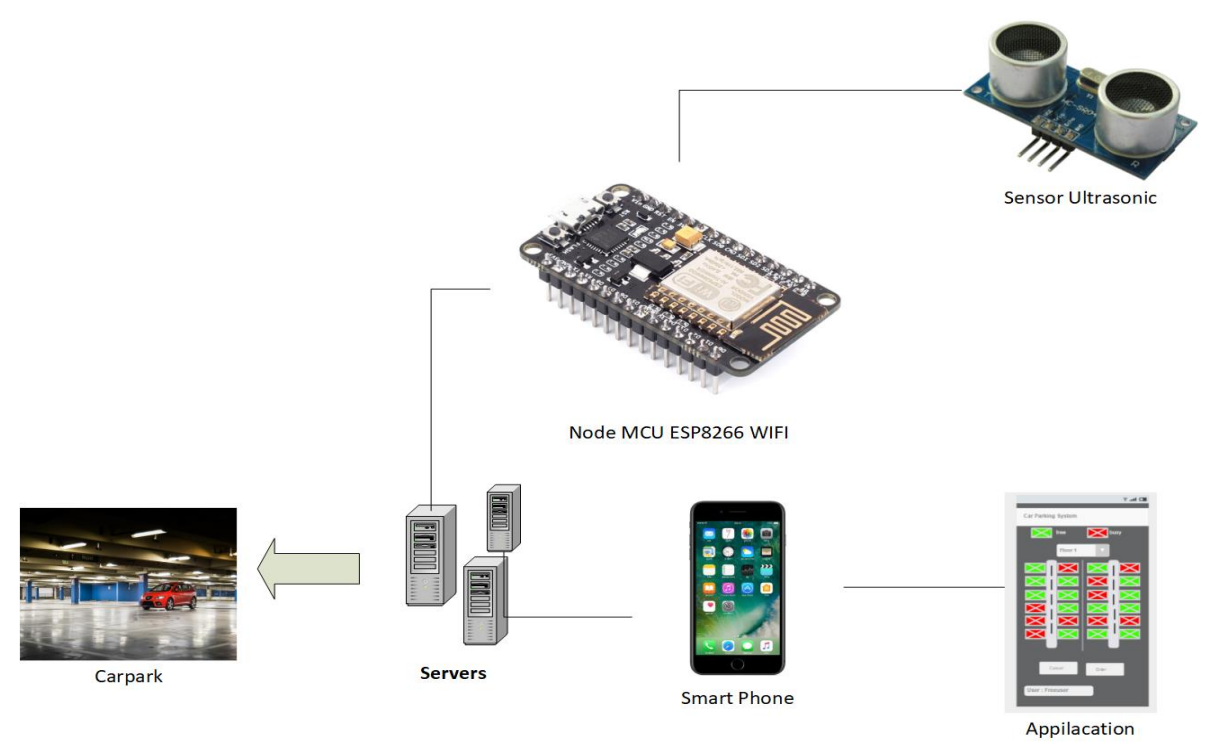

Fig. 1. Conceptual Framework

Table 2. Hardware and Software Specification

\begin{tabular}{|l|l|l|}
\hline & \multicolumn{1}{|c|}{ Standard Client } & \multicolumn{1}{c|}{ Standard Server } \\
\hline Hardware & - Microcontroller Arduino (NodeMCU) & - Microcomputer \\
& - Ultrasonic Module & \\
\hline Software & - Android & - Windows 7 or upper \\
& & - Android Studio 2.2.3 \\
& & - Arduino Software \\
& & - Apache \\
& & - MySQL \\
& & - Firebase \\
\hline Network & $-3 \mathrm{G} / 4 \mathrm{G} / \mathrm{Wi}-\mathrm{Fi}$ & - Dual 100 Mbps \\
& & - Internet \\
\hline
\end{tabular}

The database analysis was conducted and the design was created by considering the functions or key competence of the system to store data inclusively, so that it was usable. This research classified the relevant people or the users into two main groups: users or members and administrators. the users or members must apply for registration first in order to access the data of the available parking spaces. The administrators have more rights to access the system to handle the parking data by adding or editing the parking locations and issue reports of daily access of vehicles. The analysis details are shown in the Class Diagram, Figure 2. 


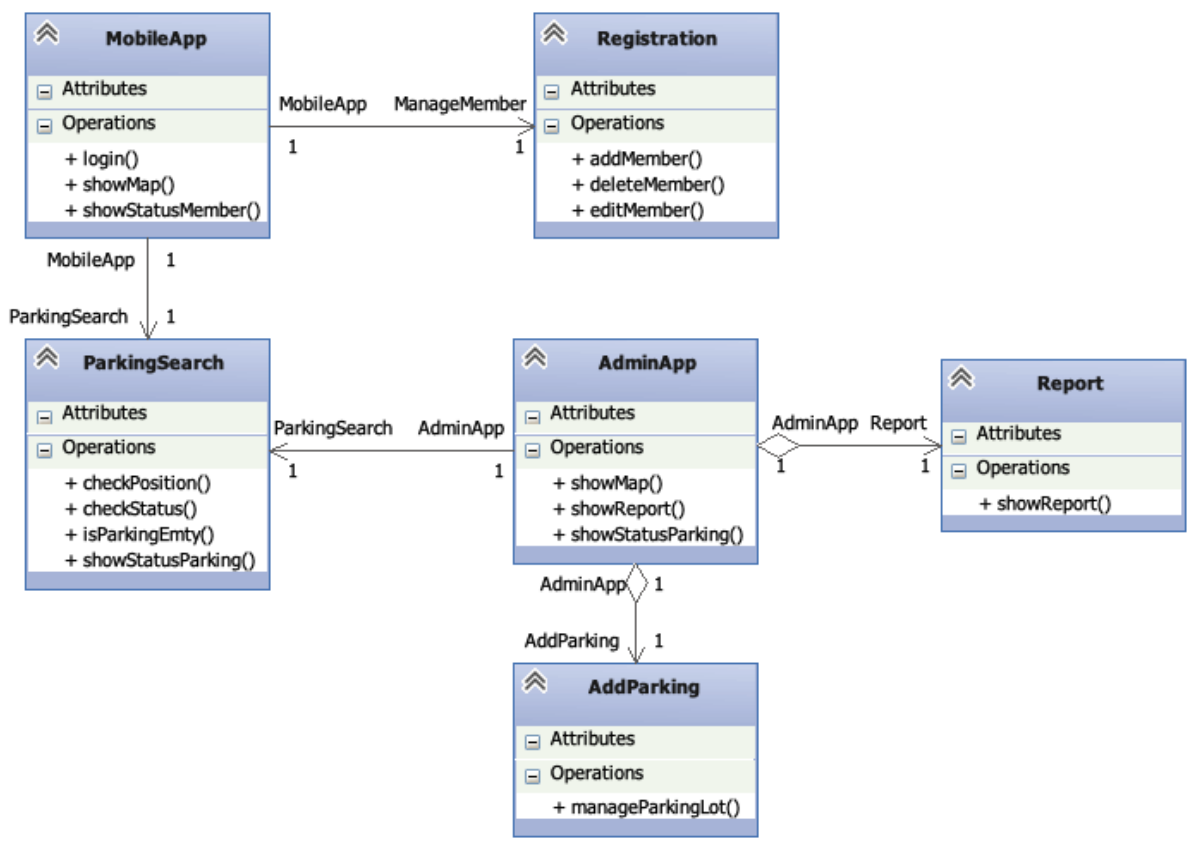

Fig. 2. Class Diagram

This research designed the mobile application to support assorted sizes of Android smartphone screens (Responsive Design). One design was applicable to all screen sizes. The development tools were programming languages and software including Java, PHP, JavaScript, CSS, Bootstrap Android Studio, and Arduino Software, and the network software to serve web applications, which was Apache. Software used for database management were MySQL and Firebase. Open source software was selected since there is no cost or any expense. Four prominent features that would enhance the efficiency of car parking management were proposed in this research, which can provide the users with information to make decisions when parking. Moreover, the relevant people in the parking area management can apply the statistics to planning for car parking construction or improvement. The details of the four prominent features are as follows:

- Checking the status and location of car parking: Sensors are used to detect whether there is a car in a parking space or not. If not, the status is recorded as 'Empty' in the database. On the other hand, if there is a car in the parking space, the record in the system changes with a note of the date and time of the change. For this reason, the users can be notified of this data and the data can be used for the reports.

- Notification of car parking status and location: Data that was received from the sensors and recorded in the database will be used to notify the users. The developed and designed system supports the mobile application and Line Application. When the sensors detect that there is or is not a car in the parking 
space, it notifies the change in status to the members or users with the result that they can decide where to park their car without wasting time.

- Car parking space management: This part was developed for the administrators. In case of more parking spaces being provided, the administrator would be able to add the data and edit the details of each parking space. For example, if the parking lot is under reconstruction or access is not allowed, the administrators will edit the data on the system from 'available' to 'unavailable'. This function will increase the efficiency of the developed mobile application to provide the most recently updated data.

- Reporting: Daily reports of car parking utilization will be created as the reference and support for car parking improvement or to provide more space to the users. The issued reports are in MS Excel format, which the relevant personnel can use for further planning.

\section{$4 \quad$ Results and Discussion}

Regarding the results of the mobile application, the first part is the registration application. The development results are shown in Figure 3, where it can be seen that the information used for the registration application were Name, E-mail address, and Password. After the application is completed, the users will be able to access the system by entering their e-mail address and password.

The next part is the development results of checking and notifying the status and position of car parking, as shown in Figure 4. On the left of the figure is the use of the mobile application to check whether a parking space is available or not, which the user can access.

On the right is the notification of the 'available' or 'non-available' status via social media, which is the Line application. A photo displaying the status of the car parking area is sent to the user's account. The development of the mobile application supports its performance and notification via the Line application. This minimizes the limitations of the conventional system, which the users have to access through a web application, and push notification was inactive when the status of the parking space changed. The development allows the users to receive the automatic notifications when the parking space is occupied or free without accessing the web application. 

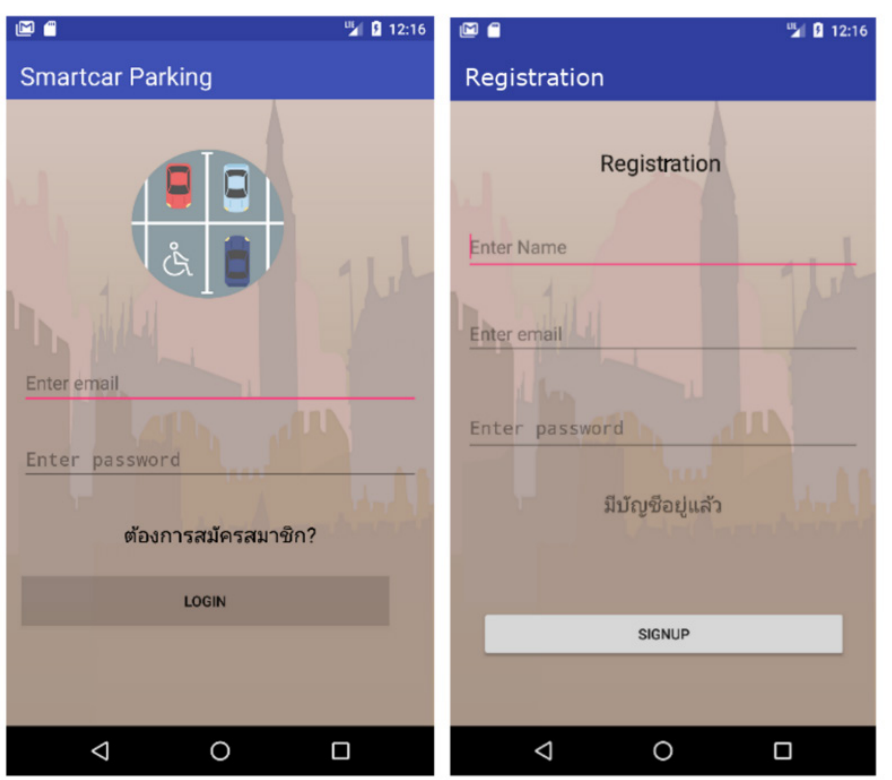

Fig. 3. Login and Registration Interface for User

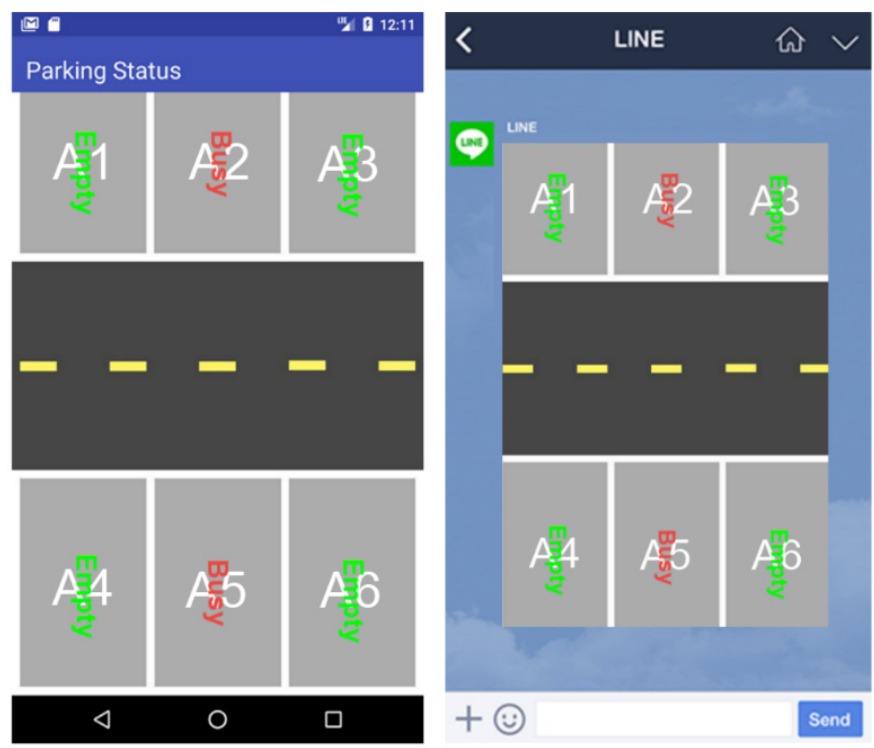

Fig. 4. Car Parking Status Interface

The last part is the management of the car parking area and the reporting, which only the administrators are able to access. The access results are shown in Figure 5. On the left of the figure is the management of the car parking area, where the administrators can add and edit the details of the parking space locations. The edited 
position is in white, the available space is in green, and the occupied space is in red. The photo on the right is of the task details that show the number of cars that accessed the parking area daily. The developed system can display the results of multiple floors in the parking building and the reports will show the number of cars daily on each floor. This information is very useful for planning. For example, it helps to analyze the number of cars daily compared to the parking spaces to determine whether there are enough, which will be useful for car parking improvement. Besides this, it can be used to analyze the location of the parking spaces that people frequently or rarely use and examine the reasons and causes, such as the location is too far or there is no roof.
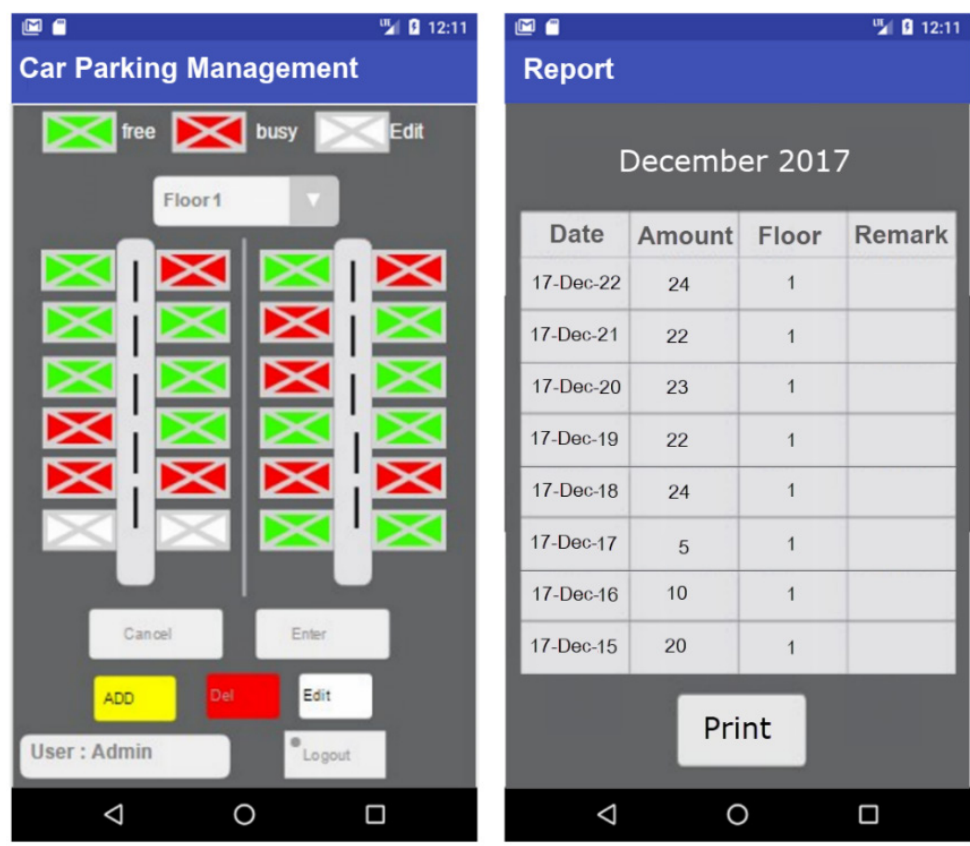

Fig. 5. Car Parking Management and Report Interface

\section{Conclusion}

The development results of the use of RFID and IoT allowed the users who were the members to access the status of a car parking space whether it was available or not. Furthermore, the system sent the automatic notifications to the users in case of the change of parking space status, which facilitated the users' parking and saved their time and fuel. Moreover, with the developed mobile application, the users did not need to access the web application all of the time, which helped the users to save time. In addition, it minimized the limitations of the conventional application.

The development results were also very beneficial for other groups of users such as the administrators, executives, and other relevant people who can apply the information for planning and management such as to analyzing the sufficiency of the 
car parking area compared to the actual usage, the need for improvement or the construction of new car parking, and the budgeting for construction. All information will support and help the users to save time. Besides this, the system suggested in this research could be applied to the smart car parking in each area or of each agency as the supportive tool of the management for real-time data storage.

For further research, a mobile application should be developed to provide the parking space reservation for both the Android and IOS operating systems in order to make it more practical for all user groups.

\section{References}

[1] V. Yiengprugsawan, J. Berecki-Gisolf, R. McClure, M. Kelly, S. A. Seubsman, A. C. Sleigh, "The effect of injuries on health measured by short form 8 among a large cohort of Thai adults.," PloS one, vol. 9, no. 2, pp. e88903, 2014 https://doi.org/10.13 71/journal.pone. 0088903

[2] K. Yoh, T. Okamoto, H. Inoi, And K. Doi,"Comparative study on foreign drivers' characteristics using traffic violation and accident statistics in Japan.," IATSS research, vol. 41, no. 2, pp. 94-105, 2017. https://doi.org/10.1016/j.iatssr.2017.06.004

[3] C. Chaichana, and S. Kaewtathip, "Emergency Response for Thailand Energy $\begin{array}{lllll}\text { Sector.," Energy } \quad \text { Procedia, vol. } & 100, & \text { pp. } & \text { 459-462, } & 2016 .\end{array}$ https://doi.org/10.1016/j.egypro.2016.10.202

[4] R. Estepa, A. Estepa, J. Wideberg, M. Jonasson, and A. Stensson-Trigell, "More Effective Use of Urban Space by Autonomous Double Parking.," Journal of Advanced Transportation, 2017. https://doi.org/10.1155/2017/8426946

[5] M. E. Beqqal, and M. Azizi, "Taxonomy on IoT Technologies for Designing Smart Systems.," International Journal of Interactive Mobile Technologies (iJIM), vol. 15, no. 2, pp. 182-191, 2018. https://doi.org/10.3991/ijim.v12i5.8831

[6] N. Chen, and Q. Yue, "Campus Intelligent Safety Supervision System Based on RFID.," International Journal of Online and Biomedical Engineering (iJOE), vol. 13, no. 11, pp. 152-161, 2017. https://doi.org/10.3991/ijoe.v13i11.7663

[7] X. Jia, Q. Feng, T. Fan, and Q. Lei, "RFID technology and its applications in Internet of Things (IoT).," In Consumer Electronics, Communications and Networks (CECNet), 2012 2nd International Conference, IEEE, pp. 1282-1285, 2012. https://doi.org/10.1 $109 /$ cecnet.2012.6201508

[8] J. Posada, C. Toro, I. Barandiaran, D. Oyarzun, D. Stricker, R. De Amicis, and I. Vallarino, "Visual computing as a key enabling technology for industrie 4.0 and industrial internet.," IEEE computer graphics and applications, vol. 35, no. 2, pp. 26-40, 2015. https://doi.org/10.1109/mcg.2015.45

[9] R. Wenge, X. Zhang, C. Dave, L. Chao, and S. Hao, " Smart city architecture: A technology guide for implementation and design challenges.," China Communications, vol. 11, no. 3, pp. 56-69, 2014. https://doi.org/10.1109/cc.2014.6825259

[10] Y. I. Daradkeh, M. Aldhaifallah, D. Namiot, "Mobile Clouds for Smart Cities.,"

[11] International Journal of Online and Biomedical Engineering (iJOE), vol. 13, no. 1, pp. 7686, 2017

[12] G. Anusooya, C. Jackson, K. Sathyarajasekaran, and K. Kannan, "RFID Based Smart Car Parking System.," International Journal of Applied Engineering Research, vol. 12, no. 17, pp. 6559-6563, 2017 
[13] S. S. Thorat, M. Ashwini, K. Akanksha, L. Sneha, and C. Mamta, “IoT Based Smart Parking System Using RFID., " International Journal of Computer Engineering In Research Trends, vol. 4, no. 1, pp. 9-12, 2017

[14] S. P. Samuel, B. Kishore, S. P. Chandran, and V. Kameshwaran, "RFID Based Smart Car Parking System Using IOT.," International Journal on Recent and Innovation Trends in Computing and Communication, vol. 6, no. 2, pp. 27-31, 2018

[15] D. Sathya, and S. Kumaresan, S. "Smart-Parking System Based On Rfid And Gsm Technology.," International Journal of Scientific \& Engineering Research, vol. 8, no. 5, pp. 116-121, 2017

[16] H. Singh, C. Anand, V. Kumar, and A. Sharma, "Automated Parking System With Bluetooth Access.," International Journal of Engineering and Computer Science, vol. 3, no. 5,2014

[17] T. N. Pham, M. F. Tsai, D. B. Nguyen, C. R. Dow, and D. J. Deng, “ A cloud-based smartparking system based on Internet-of-Things technologies.," IEEE Access, vol. 3, pp. 15811591, 2015. https://doi.org/10.1109/access.2015.2477299

[18] R. Renuka,and S. Dhanalakshmi, "Android-Based Smart Parking System Using Slot Allocation and Reservations.," ARPN Journal of Engineering and Applied Sciences, vol. 10, no. 7, pp. 3116-3120, 2015.

[19] E. Karbab, D. Djenouri, S. Boulkaboul, and A. Bagula, "Car park management with networked wireless sensors and active RFID.," In Electro/Information Technology (EIT), 2015 IEEE International Conference, IEEE, pp. 373-378, 2015. https://doi.org/10.11 $\underline{09 / \text { eit.2015.7293372 }}$

\section{Acknowledgement}

This research was financially supported by Prince of Songkla University, Surat Thani Campus.

\section{Authors}

Aekarat Saeliw is a lecturer at Faculty of Science and Industrial Technology, Prince of Songkla University, Surat Thani Campus. His research interest includes Information Technology and Mobile Application.

Watcharasuda Huankasin is an Assistant Professor at Faculty of Science and Industrial Technology, Prince of Songkla University, Surat Thani Campus. Her research interest includes Bioinformatics and Biotechnology.

Supattra Puttinaovarat is a PhD lecturer at Faculty of Science and Industrial Technology, Prince of Songkla University, Surat Thani Campus. Her research interest includes Geographic Information System and Information Technology.

Kanit Khaimook is an Associate Professor at Ramkhamhaeng University, Bangkok, Thailand. His research interest includes Information Technology and Statistics.

Article submitted 2019-01-05. Resubmitted 2019-02-01. Final acceptance 2019-02-19. Final version published as submitted by the authors. 